University of Nebraska - Lincoln

DigitalCommons@University of Nebraska - Lincoln

Architectural Engineering -- Faculty Publications

Architectural Engineering and Construction,

Durham School of

$9-2003$

Performance Review of Indoor Noise Criteria

Lily M. Wang

University of Nebraska - Lincoln, lwang4@unl.edu

Erica Eileen Bowden

University of Nebraska - Lincoln

Follow this and additional works at: https://digitalcommons.unl.edu/archengfacpub

Part of the Architectural Engineering Commons

Wang, Lily M. and Bowden, Erica Eileen, "Performance Review of Indoor Noise Criteria" (2003).

Architectural Engineering -- Faculty Publications. 19.

https://digitalcommons.unl.edu/archengfacpub/19

This Article is brought to you for free and open access by the Architectural Engineering and Construction, Durham School of at DigitalCommons@University of Nebraska - Lincoln. It has been accepted for inclusion in Architectural Engineering -- Faculty Publications by an authorized administrator of DigitalCommons@University of Nebraska Lincoln. 


\title{
Performance Review of Indoor Noise Criteria
}

\author{
Lily M. Wang and Erica E. Bowden \\ Architectural Engineering Program, Univ. of Nebraska - Lincoln, 200B PKI, 1110 S. $67^{\text {th }}$ Street, \\ Omaha, NE 68182-0681
}

\begin{abstract}
$\underline{\text { Abstract }}$
Currently there are a number of indoor noise criteria used to quantify the level of background noise in rooms, including Noise Criteria (NC), Balanced Noise Criteria (NCB), Room Criteria (RC), Room Criteria Mark II (RC Mark II) and others. This paper reviews the pros and cons of each of these and then compares the values measured in existing classrooms in the Omaha area. The authors are in the process of subjectively comparing these various criteria to determine which method best correlates with human perception. The subjective testing methods and preliminary results are discussed.
\end{abstract}

\section{Introduction}

Acoustic specialists have used various criteria over the decades to quantify human perception of the background noise in a room. Noise Criteria (NC), developed in 1957, is one of the earliest methods to be widely accepted (Beranek and Ver 1992). This system provides a one-number rating, determined by comparing the background sound levels to a set of defined NC curves. The curves were developed following measurements made in several commercial spaces, and include octave bands from $63 \mathrm{~Hz}$ to $8000 \mathrm{~Hz}$. The shape of the curves approximates the equal loudness contours developed in the early 1930's by Fletcher and Munson (1933).

$\mathrm{NC}$ is still widely used today, in part due to ease of use. A simple tangency method is employed where the $\mathrm{NC}$ rating is given by the lowest $\mathrm{NC}$ curve that lies above all of the measured data. Unfortunately, the noise spectrum does not necessarily follow the shape of the NC curves, and an excessively loud component in any one frequency band may control the overall rating.

Additionally, the NC procedure does not sufficiently differentiate between different sound spectra. Consequently two newer methods were developed and are currently recommended by ANSI Standard S12.2-1995: Balanced Noise Criteria (NCB) and Room Criteria (RC). These two systems provide not only a sound level rating but also a quality descriptor that gives an indication of the frequency content of the noise. "Rumbly" or "vibrational" ratings indicate excessive low frequency content, while extreme high frequency content is described as "hissy".

Besides evaluation of spectral quality, the NCB criteria differ from NC by including steeper slopes at high frequencies (corresponding to lower acceptable levels), and by taking into account the 16 and $31.5 \mathrm{~Hz}$ octave bands. The NCB rating is found by calculating the Speech Interference Level (SIL), which is an average of sound pressure levels in the 500, 1000, 2000, and $4000 \mathrm{~Hz}$ octave bands: 


$$
S I L=\frac{1}{4}\left(S P L_{500}+S P L_{1000}+S P L_{2000}+S P L_{4000}\right)
$$

The RC methodology differs significantly from the NC technique, both in development and application. The original RC method was developed from measurements made in unoccupied office buildings by Blazier (1981). The RC curves follow a constant slope of negative five decibels per octave band, extending from the $16 \mathrm{~Hz}$ to $4000 \mathrm{~Hz}$ octave bands. The curves are traditionally used in evaluation of spaces where the mechanical system is the primary noise source. The rating is found by calculating $\mathrm{L}_{\mathrm{MF}}$, which is the average of the mid-frequency sound pressure levels in the 500, 1000, and $2000 \mathrm{~Hz}$ octave bands:

$$
L_{M F}=\frac{1}{3}\left(S P L_{500}+S P L_{1000}+S P L_{2000}\right)
$$

Further improvements on the RC methodology have been suggested by Blazier, resulting in Room Criteria Mark II (RC Mark II) (ASHRAE 1999). The RC Mark II curves are identical to the RC curves, with the exception that the Mark II curves are slightly less lenient in the $16 \mathrm{~Hz}$ octave band. The $\mathrm{L}_{\mathrm{MF}}$ calculation remains the same, but an additional quality descriptor of "roaring" is included for excessive mid-frequency noise. The RC Mark II also includes a Quality Assessment Index (QAI) that provides an estimate of occupant evaluation, ranging from "acceptable" to "objectionable". The QAI is found using spectral deviations between the measured levels and the RC contour levels.

Two benefits of the RC Mark II and NCB methodologies are that they remain relatively easy to use and provide approximations of subjective responses to background noise. The RC Mark II curves were designed to account for low-frequency noise that fluctuates slowly, but this can unnecessarily penalize non-fluctuating mechanical systems. Conversely, the NCB curves are best applied to "well-behaved" mechanical systems, and therefore are inadequate for systems with fan-surging and turbulence (Schomer 2000).

Schomer developed Room Noise Criteria (RNC) in an attempt to bridge the gap between NCB and RC (2000). RNC involves testing for turbulence and low-frequency surging in background noise; if such components are present, then the background noise must be compared to stricter guidelines. Well-behaved systems are not penalized in this manner, however. A tangent method is incorporated for ease of rating, but RNC currently does not have a spectral quality assessment.

Other methods have been suggested over the years, including Sound Communication (SC) Curves, Perceived Noise Criteria (PNC), alternate NC (NCA) curves, Noise Rating (NR) curves, and A, B, and C-weighting networks (Tocci 2000). SC, PNC, and NCA are not commonly used in architectural acoustics, but NR is regularly used abroad. The weighting networks have appropriate applications as well, with B-weighting being used least often. 


\section{$\underline{\text { Limitations in Current Criteria }}$}

There is currently no consensus among experts on which criteria system works the best because data correlating the various criteria to actual human perception is lacking. Several limitations still remain in NCB, RC, and the newer proposed criteria for the following reasons:

\section{1) Many were developed based on experience or empirical evaluation rather than research data.}

While experience is a powerful tool and a perfectly valid method of development, additional research is merited to support the use of the newer criteria. The current methods are not equally appropriate in rating mechanical systems noise because much of their support is based on specific applications. Additional research would verify when extrapolations from the base experiences are suitable.

\section{2) None of the current methods sufficiently characterizes the effects of:}

- Discrete tones - Certain types of mechanical equipment, including motors and fans, are known to emit low-frequency pure tones under $350 \mathrm{~Hz}$. Because the audible range for human hearing is generally thought to lie between 20 and 20,000 Hz, some low frequency pure tones might be "felt" as well as heard in the form of a non-diffuse sound field. Higher frequency pure tones may be even more audibly disturbing.

- Time-varying level fluctuations - Again, the most common examples of this are seen in building mechanical systems, which are continually adjusting to the changing thermal demands of the space. Depending on time of day, season, occupancy, and other factors, the equipment might be operating near peak-capacity or far below it. Certain equipment operates in direct accordance with these fluctuations, such as variable air volume boxes, variable frequency drives, and dampers or fans associated with air handling unit economizer cycles. Fan surge noise can be particularly troublesome acoustically. While RNC attempts to analyze cyclic variation of low-frequency sounds produced in large ventilation systems, additional research of this method would verify if other level fluctuations follow the same criteria (Tocci 2000).

\section{3) The criteria are based on speech interference and/or annoyance tests for adults with normal hearing, not hearing-impaired individuals.}

The Americans with Disabilities Act of 1990 ensured that the building industry would endeavor to better accommodate persons with disabilities. In the acoustical community, focus has been placed in particular on classroom acoustics to guarantee that hearingimpaired students are not at a disadvantage. In addition to schools, an addendum to the current criteria which accounts for hearing-impaired perception could be used in spaces such as nursing homes, hospitals, senior citizen centers, churches, and any spaces accommodating the elderly. Simply designing more conservatively is insufficient because it does not take into account the differences in hearing processes and subjective perception between normal and hearing-impaired persons. 


\section{Comparison of Ratings in Omaha-Area Classrooms}

In a recent study completed in Omaha, Nebraska, background noise levels were measured in eight local middle and high school classrooms (Bowden et al 2002). The measurements were made with the mechanical systems running, all auxiliary instructional equipment turned off, in an unoccupied condition. Calculation of the noise criteria ratings for several of the classrooms resulted in interesting differences; Table 1 shows a representative subset of the data. The ratings agreed well for classroom 2, but not for 1 and 3.

General observations about the correlations of the criteria shown in Table 1 and the other classrooms included in the study can be made. These findings agree in general with a larger study completed by Tocci, which compared the NC, NCB, RC, and RC Mark II methods (2000).

Table 1 - Noise criteria ratings for background noise measured in unoccupied classrooms

\begin{tabular}{|c|c|c|c|c|}
\hline Classroom & $\begin{array}{c}\text { NC } \\
\text { (Schultz 1968) }\end{array}$ & $\begin{array}{c}\text { NCB } \\
\text { (ANSI 1995) }\end{array}$ & $\begin{array}{c}\text { RC } \\
\text { (ANSI 1995) }\end{array}$ & $\begin{array}{c}\text { RC Mark II + } \\
\text { QAI } \\
\text { (ASHRAE 1999) }\end{array}$ \\
\hline $\mathbf{1}$ & 51 & 40 -Rumbly & 42-Rumbly & $\begin{array}{c}\text { 42-Roaring, } \\
\text { Marginal }\end{array}$ \\
\hline $\mathbf{2}$ & 30 & 30-Hissy & 31-Hissy & $\begin{array}{c}\text { 31-Hissy, } \\
\text { Marginal }\end{array}$ \\
\hline $\mathbf{3}$ & 30 & 30-Hissy & 31-Hissy & $\begin{array}{c}\text { 31-Rumbly, } \\
\text { Marginal }\end{array}$ \\
\hline
\end{tabular}

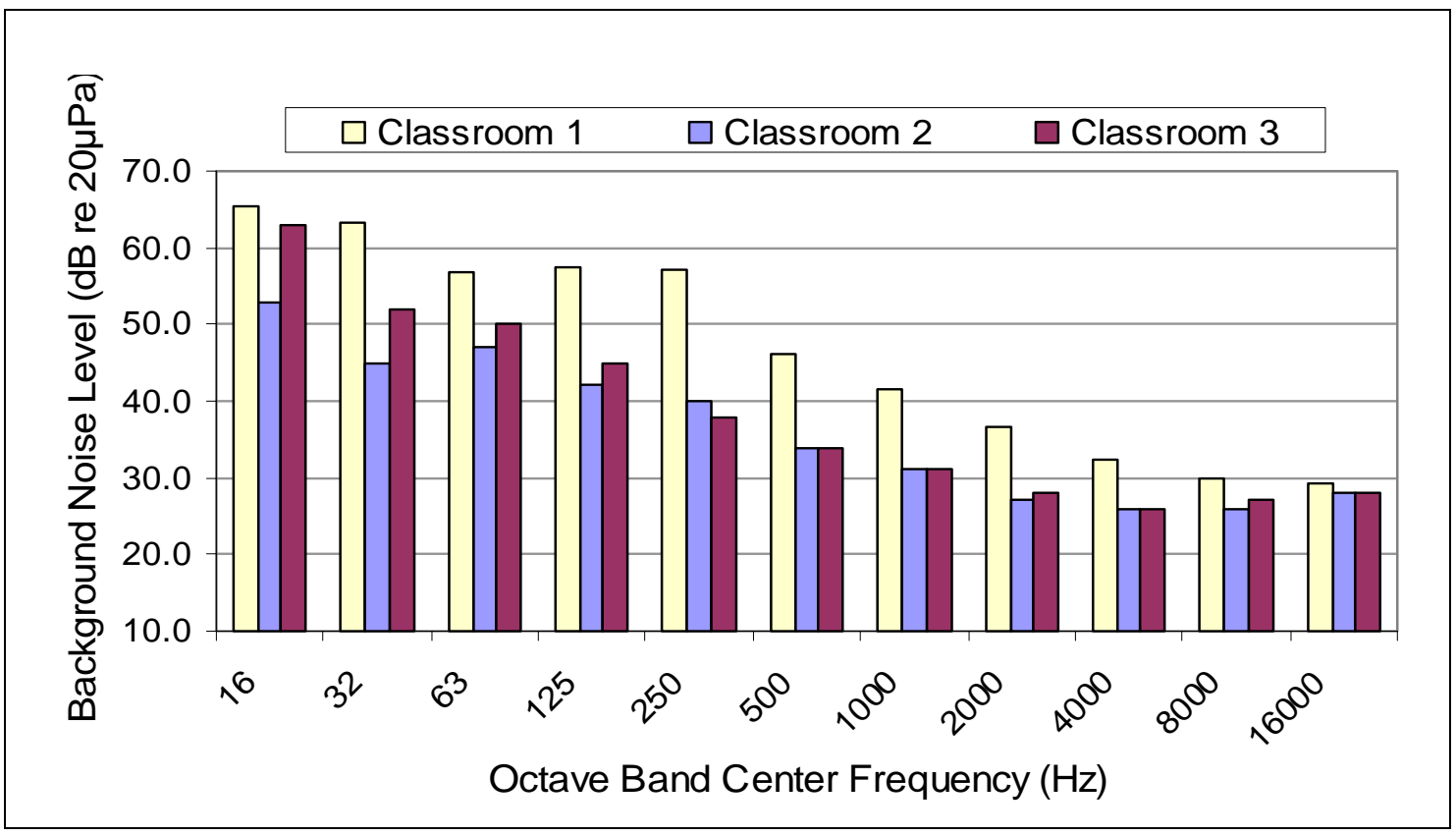

Figure 1 - Background noise spectra measured in unoccupied classrooms 
1) $\mathrm{NC}$ ratings are generally higher than $\mathrm{NCB}$. The high levels found in the 125 and 250 $\mathrm{Hz}$ octave bands of classroom 1 can be seen in Figure 1. These two bands force the NC rating above that found in the other bands. Conversely, the rating found with NCB is much lower because it is found with the SIL, which does not include either of these frequency bands. However, the NCB "rumbly" rating found in classroom 1 does indicate that those low frequencies would be dominant.

2) In general, $\mathrm{NC}$ ratings are higher than $\mathrm{RC}$ and $\mathrm{RC}$ Mark II, but this can vary. The reasons behind this are similar to those found with NCB, as RC and RC Mark II ratings are calculated based on a three band average of 500, 1000, and $2000 \mathrm{~Hz}$.

3) Numerical ratings of RC and RC Mark II agree fairly well with NCB on average. Spectral quality ratings can vary, though. In classroom 3, we found NCB and RC described the spectrum as hissy, whereas RC Mark II labeled it as rumbly. The reasons behind this are slightly complicated and would require a more in-depth discussion of the calculation methods. For the purposes of this paper, it is sufficient to note that spectral quality ratings can differ significantly between these criteria.

4) $\mathrm{RC}$ and RC Mark II are identical in their numerical ratings, but differences can be found in spectral quality. Exact comparison is difficult because RC only evaluates rumble and hiss, whereas RC Mark II uses rumbly, roaring and hissy categories.

5) There is generally better agreement between numerical ratings for spectra that have a hissy quality than for spectra with a rumbly quality (classrooms 2 and 3 versus classroom 1). This stems from the fact that the numerical ratings are based on the tangency method for $\mathrm{NC}$, but on mid to high frequency values for the others; thus, if the tangency occurs in the high frequency region (thereby being labeled hissy), there is greater correlation between numerical ratings.

\section{Subjective Testing}

The authors are currently conducting research to address the problems outlined above. The purpose is to determine an indoor noise criteria system that best characterizes human perception of different background noise environments. This determination will be made from studying subjective data on task performance, speech intelligibility, and annoyance perception by humans when exposed to various background noise conditions. Such data demonstrate how the background noise affects productivity, understanding, and occupant perception.

Three general types of background noise situations will be used: (1) background noise spectra with simple characteristics, including balanced, rumbly, roaring and hissy types, (2) background noise spectra that have prominent discrete tones, and (3) noise with time-varying fluctuations. The quantitative evaluations of human reactions will be correlated to current noise criteria, including NCB, RC, RC Mark II, and RNC, to determine which criteria perform best in each circumstance. Results will then be used to define or refine noise criteria that account for more complicated spectra, such as with pure tones or time-varying fluctuations. 
The noise spectra will be computer generated to mimic ambient levels commonly encountered in real world environments. First neutral test sounds will be created using random noise which follows the shape of an equal loudness contour. These contours mark the levels across frequency that are perceived by humans to be of equal loudness $(65$ decibels at $50 \mathrm{~Hz}$ is roughly equivalent to 40 decibels at $1000 \mathrm{~Hz}$, because humans are more sensitive to mid and high frequency sound than low frequency). Other uncomplicated spectra will be constructed next, including those with rumbly, roaring, or hissy character. These will be simulated by increasing the level of the low, mid, or high frequency components above the level at other frequencies.

Two types of complicated background noise cases will be used as well. Those with apparent discrete tones will be tested, with the single tone occurring at a variety of frequencies and at varying levels compared to the rest of the background noise. Lastly, time-varying fluctuations will be constructed, shifting in amplitude (how large is the change in level?) and in frequency (how fast does the change in level occur?).

Both normal and hearing-impaired test subjects will be recruited. They will be asked to complete task completion, annoyance level, and speech intelligibility tests while exposed to the different background noise spectra. Task completion tests will be conducted using a series of self-administered computerized tasks developed by the National Research Council Canada, including a typing test and proofreading test (Scovil et al 1995a, 1995b, 1995c). Annoyance levels will be rated by the test subjects after the office tasks are performed. Finally, speech intelligibility will be run using standardized word lists in a controlled space, in accordance with ANSI Standard S3.2-1989.

All of the subjective test data will be correlated to the various noise criteria to establish which system performs best in each circumstance. Results will then be used to define or refine noise criteria to account for more complicated background noise cases, such as those with discrete tones and time-varying fluctuations. Preliminary results are to be presented at the AEI 2003 Conference.

\section{$\underline{\text { Summary }}$}

Proper background noise criteria are imperative, so that problems can be correctly diagnosed in existing buildings and prevented in newly constructed or renovated buildings. Currently a number of indoor noise criteria methods are in use or have been proposed, including NC, NCB, RC, RC Mark II, and RNC. Many designers of building mechanical systems still use basic NC, and manufacturers continue to present product noise data in $\mathrm{NC}$ format. These groups are tentative about using the newer methods because they have either not been exposed to them or are uncertain as to which work best in different applications. Even acoustical consultants are unsure about which criteria performs best. As shown in this paper, inconsistencies are certainly common among the current criteria when used to rate noise in classrooms. Research is consequently being undertaken by the authors to substantiate current criteria with subjective testing results. 


\section{Acknowledgments}

This research has been supported by the University of Nebraska - Lincoln Layman Foundation, the Institute of Noise Control Engineering, and the American Society of Heating, Refrigeration and Air-Conditioning Engineers.

\section{$\underline{\text { References }}$}

ANSI. (1989). ANSI Standard S3.2-1989: Method for Measuring the Intelligibility of Speech Over Communication Systems. Acoustical Society of America, Melville, NY.

ANSI. (1995). ANSI Standard S12.2-1995: Criteria for Evaluating Room Noise. Acoustical Society of America, Melville, NY.

ASHRAE. (1999). ASHRAE Handbook: HVAC Applications. American Society of Heating, Refrigerating, and Air-Conditioning Engineers, Atlanta.

Beranek, L. and I. Ver. (1992). Noise and Vibration Control Engineering: Principles and Applications. Wiley-Interscience.

Blazier, W. E., Jr. (1981). "Revised noise criteria for application in the acoustical design and rating of HVAC systems." Noise Control Eng. J., 16, 64-73.

Bowden, E. E., L. M. Wang and D. T. Bradley. (2002). "Classroom acoustics in Omaha, Nebraska: measurements and outreach." J. Acoust. Soc. Am., 112, 2430(A).

Fletcher, H. F. and W. A. Munson. (1933). "Loudness, its definition, measurement and calculation." $J$. Acoust. Soc. Am., 5, 82-108.

Schomer, P. D. (2000). "Proposed revisions to room noise criteria." Noise Control Eng. J., 48(3), 85-96.

Schultz, T. J. (1968). "Noise-criterion curves for use with the USASI preferred frequencies." J. Acoust. Soc. Am., 43, 637-638.

Scovil, C. Y., G. R. Newsham and J. A. Veitch. (1995a). Proofreading Task: Software to Measure the Speed and Accuracy of Proofreading from a Computer Screen. Internal Report Number 701. Institute for Research in Construction, National Research Council Canada, Ottawa, Canada.

Scovil, C. Y., G. R. Newsham and J. A. Veitch. (1995b). Conveyor Belt Task: Software to Test Reaction Time using Targets on a Simulated Conveyor Belt. Internal Report Number 702. Institute for Research in Construction, National Research Council Canada, Ottawa, Canada.

Scovil, C. Y., G. R. Newsham and J. A. Veitch. (1995c). Typing Task: Software to Measure the Speed and Accuracy with which Presented Text is Typed. Internal Report Number 700. Institute for Research in Construction, National Research Council Canada, Ottawa, Canada.

Tocci, G. C. (2000). "Room noise criteria - The state of the art in the year 2000." Noise/News Intl., 8, 106-119. 